\title{
Investigation of Energetic Particle Distribution from High-Order Detonation of Munitions
}

\author{
Authors: Mike, Tracey, Matt, Sonia, Nathalie Mai, Seibati, Melissa
}

Abstract: Military training with munitions containing explosives has been shown to result in the deposition of energetic materials on ranges. These residues contain compounds that can be toxic and thus may result in human health impacts when they migrate off range. Models exist that predict the spatial and mass distribution of particles, but they have proven to be difficult to apply to detonating munitions. We have conducted a series of tests to determine if modeling results can be directly applied to simple detonation scenarios. We have also command detonated several rounds to obtain an initial indication of the high-order detonation particle distribution heterogeneity. The detonation tests indicate that particle distributions will be quite heterogeneous and that the model used did not adequately describe the distribution of residues for a detonation. This research will need to be expanded to build an empirical database sufficient to allow the refinement of existing models. Research on low-order detonation particle spatial distributions will also need to be conducted, as low-order detonations will result in higher mass deposition than high-order detonations. The resultant models may then be incorporated into range management procedures to protect human health and military range assets. (193 Words)

\section{Introduction}

Training with live munitions is an integral part of military preparedness. Any munition that is fired contains energetic materials, such as propellants, explosives, or incendiaries. Compounds that make up these materials can be found on training ranges [1-4]. Evidence includes energetics in soil and water samples taken from active and legacy ranges and the impacts to wildlife and vegetation on training ranges [5-8]. Many energetic compounds are water soluble and will migrate to groundwater, compromising drinking water resources and threatening human health and range sustainability [9-12].

In the US, a new class of ordnance called insensitive munitions (IM) is being certified for use on training ranges. These munitions contain highly soluble compounds in their insensitive highexplosive formulations [13-16]. Up to $99 \%$ of compounds such as ammonium perchlorate (AP), Nitrotriazolone (NTO) and Nitroguanadine (NQ) will dissolve out of the high-order detonation residues upon exposure to liquid water [17]. The impact emerging explosive and propellant formulations and constituent compounds will have on range sustainability is currently being studied [18].

Models have been used to attempt to predict the impact that training with live munitions will have on training ranges [19-22]. Empirical data is available on the mass of energetics resulting from the firing and detonation of munitions $[23,24]$. These data include some spatial information in the form of the overall residues deposition area. Particle size distribution data is also available for several munitions that detonated low-order (Table 1) $[\mathbf{1 0}, \mathbf{1 3}, \mathbf{2 5}]$. What is not available is sufficient empirical data on the physical characteristics and spatial distribution of particulate residues to refine existing models so that they can be used to effectively predict the spatial distribution of particles from munitions detonations [19].

Analysis of current particle dispersion models indicates that they are based on a near-uniform distribution of residues [26]. For high-order detonations of munitions, there are no empirical data in the literature to confirm the assumption of uniform particle distribution. Research on mass distribution of energetic residues from high-order detonations indicates that residues tend to be very fine and to form near-annular dispersion patterns in low-wind situations (Figure 1)[27]. Very limited spatial distribution data are available from these tests. Low-order detonations make up a small percentage of munitions detonations but are the dominant source of energetics mass on ranges 
$[28,29]$. Low-order detonation residues spatial distribution, which must also be considered in particle dispersion models, will be examined in a future paper.

There is a tendency to tie explosives residues dispersion to metal fragmentation (frag) dispersal, which is only applicable if the residues are adhered to the frag [30, 31]. Models that take into account particle dispersion based on size and mass have used simulated or very limited empirical data [2][19][32]. Additional empirical data for spatial distribution of energetics from high-order detonations of munitions are needed to better refine existing dispersion models.

\section{Methods}

We used three methods to investigate post high-order detonation explosive particle spatial distribution. In the first phase of the study, we examined past high-order detonation tests to derive a method to use the available data available to estimate gross particle distribution. In the second phase, we conducted high-order detonation tests on clean ice and measured the physical and spatial characteristics of the particles. In the third phase, we compared these results to results from unconfined detonation tests that were designed using ProSAir modeling software to determine if a single-component (Hexogen, or RDX) detonation residues dispersal pattern better resembled the model prediction or the empirical results from the field detonations [33].

\section{Phase 1: High-order detonation dispersal patterns}

High-order detonation tests have been conducted on snow for many years to estimate energetics residues mass resulting from training with live munitions $[34,35]$. The basis for these tests is to collect a representative sample of the deposition area and calculate the mass of energetics residues within that area. Replicate sampling and quality assurance procedures are conducted to ensure data quality. Data from tests conducted in 2004 [36] to characterize the distribution of residues from within demarcated live-fire detonation plumes were re-examined to determine if a rough correlation between distance from the detonation point or perceived density of the residues on snow can be made with the actual residues distribution. These factors were then applied to the deposition area to determine if this correlation may be useful to models. No quantitative measurements of particle sizes were conducted during these tests, only the mass of energetics within each area or sub-area sampled was measured.

Phase 2: Multi-component explosives spatial distribution tests

The spatial distribution of explosives residues particles from the detonation of munitions in the field was tested in March of 2015 on the Eagle River Flats impact range on Joint Base ElmendorfRichardson in Alaska. At the time of the tests, the range was covered with a moderate layer of ice $(30 \mathrm{~cm})$ and was free of snow. For these tests, we used 81-mm mortar rounds containing a multicomponent insensitive high-explosive filler (IMX-104), containing RDX, Dinitroanisole (DNAN), and NTO. All rounds were command detonated with a special fuze simulator containing Composition C4 (C4) explosive. Initiation was through a blasting cap inserted in the nose of the fuze simulator. The detonation thus occurred in a fully enclosed round (Figure 2).

Three test locations were set up on the ice at the Flats. At each location, a center detonation point was marked and concentric circles $1-\mathrm{m}$ in width out to $10-\mathrm{m}$ from the detonation point were demarcated (Figure 3). Distances between detonation points were based on high-order detonation plume sizes established during prior field-testing of 81-mm IMX-104 mortar rounds [15].

Rounds were detonated with the objective of attaining a high-order detonation. All rounds for these tests had the tail assemblies removed and the body of the round mounted vertically on an aluminum plate. We characterized the detonation based on post-detonation energetics residues. We use this quantification method rather than a qualitative assessment method such as those described in NATO STANAG AOP-39 and MIL-STD-2105 because it yields quantitative data that can be validated 
through quality assurance methods $[37,38]$. The measurement is based on the percent of explosive filler consumed during the detonation (Table 1). Note that the descriptor considers the filler as a whole. One of the advantages of the characterization method used in this study is that the method allows the analysis of the residues for the various energetic constituents that make up the energetic filler. It is thus possible to determine detonation efficiencies for energetic compounds as well as the filler as a whole.

\section{Table 1. Detonation characterization descriptors}

\begin{tabular}{|c|c|c|}
\hline Descriptor & Filler mass consumed & Munition state \\
\hline $\begin{array}{l}\text { High-order detonation } \\
\text { (HI) }\end{array}$ & $99.99 \%$ or more & $\begin{array}{l}\text { Total fragmentation of projectile body. No visible } \\
\text { particles of explosive, although soot present. }\end{array}$ \\
\hline $\begin{array}{l}\text { Low-order detonation } \\
\text { (LO) }\end{array}$ & $75 \%$ to $99.98 \%$ & $\begin{array}{l}\text { Substantial fragmentation of round with some large } \\
\text { metallic body pieces remaining. Visible particles of } \\
\text { unreacted explosive filler evident on the ground and } \\
\text { adhered to larger metal fragments. }\end{array}$ \\
\hline Partial detonation & $25 \%$ to $75 \%$ & $\begin{array}{l}\text { Little if any fragmentation of the body with most of } \\
\text { the round intact. Large chunks of explosive filler (> } \\
\mathrm{cm} \text { size) near round. }\end{array}$ \\
\hline Initiated dud & $<25 \%$ & $\begin{array}{l}\text { Fuze initiated. Intact round with some cracking at } \\
\text { nose possible. May be chunks of explosive filler } \\
\text { adjacent to the round. }\end{array}$ \\
\hline Non-initiated dud & None & $\begin{array}{l}\text { Round intact, including fuze. No ejection of } \\
\text { explosive filler. }\end{array}$ \\
\hline
\end{tabular}

The fuze simulators were loaded with $18 \mathrm{~g}$ of $\mathrm{C} 4$ explosive to trigger the desired detonation type. Initiation was by detonation cord and time fuze. As these were the first tests of this type conducted involving particle distribution, we collected samples in a variety of ways to determine how best to sample for the data needed. For high-order detonations, we were interested in both particle size and total residues mass, which we later compared to high-order residues masses from other types of sample collections [36]. Thus, particles were collected in aluminum pans screwed into the ice to investigate the particle-size to spatial-distribution relationship and the remaining visible residues were swept up to get a mass balance of the energetics following detonation (Table 2).

Table 2. Sample collection methods for Phase 2 tests

\begin{tabular}{ll}
\hline Test & Sampling Collection \\
\hline HI-1 & Collected particles from pans \\
& Swept up remaining residues for analysis \\
HI-2 & Collected particles from pans \\
HI-3 & Swept up all detonation residues for analysis
\end{tabular}

The high-order particle distribution samples, which were mixed in an ice particle matrix, were returned frozen to the analytical lab in Hanover, NH, for processing and measurement. The particles were first freeze-dried to remove the ice fragments resulting from the munition detonation. The remaining particles were examined under a microscope to determine size. Some component differentiation was possible based on particle coloration, the crystals of explosive being a dull white. The swept residues that were collected for the overall energetic residues mass estimation were melted $\left(0^{\circ} \mathrm{C}\right)$, vacuum filtered, and analyzed using methods developed by Walsh $[39,40]$. 


\section{Phase 3: Unconfined Charge}

The Phase 3 tests were conducted in an open-ended ISO container. The steel cargo container used for the tests measured approximately $6-\mathrm{x} 2.4-\mathrm{x} 2.5-\mathrm{m}$ with one open end. The container was sized according to the predicted dispersal pattern generated by the ProSAir software package [33]. A 2.5g charge of PE7 (88\% RDX) was suspended at a height of $0.5 \mathrm{~m}$ above a steel base plate on the floor of the container. A $0.75-\mathrm{g}$ penta-erythritol tetranitrate (PETN) charge was used to initiate the PE7. Fifteen pre-cleaned steel witness plates were placed in equal-area segments of one of the quadrants of the base plate. Following charge detonation, the witness plates were swiped with cotton swabs dampened with acetone. The swabs were placed in airtight jars for transportation to the analytical lab, where acetone was added until the swabs were covered. The jars were sonicated for $10 \mathrm{~min}$ and the swabs were rinsed with acetone and pressed tightly to remove the solvent. The acetone was evaporated to dryness under nitrogen gas flow and acetonitrile $50 \%$ in water was added to make up the volume to $10 \mathrm{ml}$. The solutions were filtered and aliquots were analysed using highperformance liquid chromatography.

Analyses were undertaken using an Alliance series liquid chromatography-photodiode array (LCPDA) detection system (Waters UK, Elstree, UK). Separation was carried out on ACE UltraCore $2.6 \mu$ SuperPhenylHexyl column $(4.6 \times 100 \mathrm{~mm})$ from Hichrom ltd, using a 40:60 acetonitrile/water mobile phase at a flow rate of $1 \mathrm{ml} / \mathrm{min}$. The column was maintained at $30^{\circ} \mathrm{C}$ and the injection volume was $10 \mu \mathrm{l}$. Detection was achieved at $210 \mathrm{~nm}$. The method was linear over the concentration range of 1 to $50 \mathrm{ppm}$.

\section{Results}

Phase 1: High-order detonation general dispersion patterns

High-order detonation energetics residues deposition areas for five common munitions are presented in Table 3. We have separated the data by munition size and energetic filler. For data that have been reported earlier, a reference is given. The explosive formulations include Trinitrotoluene (TNT), Composition B (Comp-B: RDX/TNT), PAX-21 (RDX, DNAN, AP), and IMX-104 (DNAN, NTO, RDX). Chemical nomenclature are given in the List of Acronyms at the end of this paper.

Table 3. Detonation residues deposition areas

\begin{tabular}{|c|c|c|c|c|c|}
\hline Munition & $\begin{array}{l}\text { Explosive } \\
\text { Formulation }\end{array}$ & $\begin{array}{l}\text { Detonation } \\
\text { Type }\end{array}$ & $\begin{array}{l}\text { Number of } \\
\text { Rounds }\end{array}$ & $\begin{array}{l}\text { Deposition } \\
\text { Area }\left(\mathrm{m}^{2}\right)\end{array}$ & Source \\
\hline $\begin{array}{l}\text { Mortar Rou } \\
60-\mathrm{mm}\end{array}$ & $\begin{array}{c}\text { Comp-B } \\
\text { PAX-21 } \\
\text { IMX-104 }\end{array}$ & $\begin{array}{l}\text { Live-fire }^{1} \\
\text { Command }^{2} \\
\text { Command }^{2}\end{array}$ & $\begin{array}{l}7 \\
7 \\
7\end{array}$ & $\begin{array}{l}220 \\
330 \\
250\end{array}$ & $\begin{array}{l}{[23]} \\
{[13]} \\
{[15]}\end{array}$ \\
\hline 81-mm & $\begin{array}{c}\text { Comp-B } \\
\text { IMX-104 } \\
\text { IMX-104 } \\
\text { IMX-104 }\end{array}$ & $\begin{array}{l}\text { Live-fire } \\
\text { Command } \\
\text { Command } \\
\text { Command }\end{array}$ & $\begin{array}{c}14 \\
7 \\
5 \\
2\end{array}$ & $\begin{array}{l}230 \\
350 \\
670^{3} \\
460\end{array}$ & $\begin{array}{l}{[23]} \\
{[15]} \\
{[41]}\end{array}$ \\
\hline $120-\mathrm{mm}$ & Comp-B & Live-fire & 8 & 450 & [23] \\
\hline $\begin{array}{l}\text { Howitzer } \\
105-\mathrm{mm}\end{array}$ & $\begin{array}{l}\text { unds } \\
\text { Comp-B }\end{array}$ & Live-fire & 13 & 530 & {$[23]$} \\
\hline $155-\mathrm{mm}$ & $\begin{array}{c}\text { Comp-B } \\
\text { TNT }\end{array}$ & $\begin{array}{l}\text { Live-fire } \\
\text { Live-fire }\end{array}$ & $\begin{array}{c}7 \\
78\end{array}$ & $\begin{array}{l}940 \\
760\end{array}$ & $\begin{array}{l}{[23]} \\
{[23]}\end{array}$ \\
\hline
\end{tabular}

\footnotetext{
${ }^{1}$ Deposition from rounds fired into an impact area
} 


\footnotetext{
${ }^{2}$ Deposition from statically (command) detonated rounds using a fuze simulator
}

${ }^{3}$ Fuze simulator booster charge increased $50 \%$ from previous test

There are differences in deposition areas within groupings of rounds and overlap between rounds of different sizes. The very small particle sizes of the high-order residues make them very susceptible to aerial transport. Variations in wind velocity will have a great effect on the residues dispersal pattern and the area of the deposition area. In tests conducted with 81-mm IMX-104 rounds, the area of deposition for five simultaneously command detonated rounds varied from 580 to $890 \mathrm{~m}^{2}$. Table 3 also contains high-order detonation residues dispersal patterns from fired $81 \mathrm{~mm}$ and 105 mm Comp-B high-explosive rounds and 155-mm TNT and Comp-B rounds that were blown in place.

Post detonation residues on snow were sampled based on a subjective perceived deposition density gradient (dark / medium / light). No consistent correlation between the estimated mass of energetics recovered and the residues density for a fired 105-mm HE round and the two 155-mm rounds that were blown in place (BIP) (Table 4). The BIP detonations are used in this analysis because of the efficiency of the detonation indicates a high-order detonation occurred during the operation. The complete deposition area was also sampled and an estimate for total residues mass was calculated as a quality assurance procedure for the test. In all three cases, the cumulative residues from the three density zones are within a factor of 2 of the estimates for the total deposition areas. The percent of residues in each of the three zones indicates that it is important that not just areas that are perceived as contaminated are sampled. The residues in "light" density zones, where there were only traces of residues on the snow surface, contributed significantly to the total mass estimate.

Table 4. Gradient-based mass distribution tests (BIP detonations) [36]

\begin{tabular}{llcccc}
\hline $\begin{array}{l}\text { Test } \\
\text { (Efficiency) }\end{array}$ & $\begin{array}{l}\text { Zone } \\
\text { Sampled }\end{array}$ & $\begin{array}{c}\text { Deposition } \\
\text { Area }\left(\mathrm{m}^{2}\right)\end{array}$ & $\begin{array}{c}\text { Est. Mass of } \\
\text { Residues }(\mathrm{mg})\end{array}$ & $\begin{array}{l}\text { Percent of } \\
\text { Residues }\end{array}$ & $\begin{array}{c}\text { Residues } / \text { Unit } \\
\text { Area }\left(\mathrm{mg} / \mathrm{m}^{2}\right)\end{array}$ \\
\hline 105-4: HI & All & 810 & 21 & - & 0.024 \\
$(99.999 \%)$ & Dark & 97 & 7.5 & $61 \%$ & 0.077 \\
& Medium & 61 & 0.3 & $2 \%$ & 0.004 \\
& Light & 650 & 4.4 & $37 \%$ & 0.007 \\
$155-1:$ BIP & All & 1200 & 16 & - & 0.013 \\
$(99.999 \%)$ & Dark & 70 & 0.3 & $2 \%$ & 0.004 \\
& Medium & 370 & 7.3 & $39 \%$ & 0.021 \\
& Light & 840 & 11 & $59 \%$ & 0.013 \\
$155-7:$ BIP & All & 1200 & 18 & - & 0.015 \\
$(99.999 \%)$ & Dark & 97 & 11 & $52 \%$ & 0.110 \\
& Medium & 320 & 6.2 & $29 \%$ & 0.019 \\
& Light & 770 & 3.9 & $19 \%$ & 0.005 \\
\hline
\end{tabular}

${ }^{1}$ Perceived density of residues on snow as determined by darkness of deposition

In the three tests for which deposition area samples were collected based on distance from the detonation point, there is an obvious correlation between distance and deposition. Results are consistent based on distance from the detonation point, with about an order of magnitude reduction in residues for each 10- $\mathrm{m}$ increase in distance from the detonation point (Table 5). There is very little difference among tests in both the estimated percent of residues and the density of those residues in each 10-m band extending out from the detonation point, even though the $81-\mathrm{mm}$ round contained $950 \mathrm{~g}$ of Comp-B whereas the $105-\mathrm{mm}$ round contained $2100 \mathrm{~g}$ of Comp-B explosive. 
For the zonal tests, a 3-m annulus surrounding the visually demarcated residues deposition area was sampled to determine if a significant amount of residues lay outside the perceived deposition area. The estimated average mass of energetic residues recovered in a 3-m annulus surrounding the demarcated deposition area was $1.6 \%$ of the total estimated mass within the demarcated area, indicating that the deposition areas were correctly demarcated.

Table 5. Zonal-based mass distribution tests (HO detonations) [36]

\begin{tabular}{llcccc}
\hline Test & $\begin{array}{l}\text { Area } \\
\text { Sampled }\end{array}$ & $\begin{array}{c}\text { Deposition } \\
\text { Area }\left(\mathrm{m}^{2}\right)\end{array}$ & $\begin{array}{c}\text { Est. Mass of } \\
\text { Residues }(\mathrm{mg})\end{array}$ & $\begin{array}{l}\text { Percent of } \\
\text { Residues }\end{array}$ & $\begin{array}{l}{ }^{2} \text { Residues } \\
\text { Density }\left(\mathrm{mg} / \mathrm{m}^{2}\right)\end{array}$ \\
\hline $81-5$ & $<10 \mathrm{~m}^{1}$ & 190 & 19 & $72 \%$ & 0.100 \\
& $10-20 \mathrm{~m}$ & 230 & 6.1 & $23 \%$ & 0.027 \\
& $>20 \mathrm{~m}$ & 380 & 1.2 & $5 \%$ & 0.003 \\
$105-3$ & $<10 \mathrm{~m}$ & 280 & 27 & $83 \%$ & 0.096 \\
& $10-20 \mathrm{~m}$ & 390 & 4.6 & $14 \%$ & 0.012 \\
& $>20 \mathrm{~m}$ & 260 & 0.8 & $3 \%$ & 0.003 \\
$105-7$ & $<10 \mathrm{~m}$ & 230 & 20 & $77 \%$ & 0.087 \\
& $10-20 \mathrm{~m}$ & 370 & 4.8 & $18 \%$ & 0.013 \\
& $>20 \mathrm{~m}$ & 350 & 1.2 & $5 \%$ & 0.003 \\
Means & $<10 \mathrm{~m}$ & 230 & 22 & $78 \%$ & 0.096 \\
$(\mathrm{n}=3)$ & $10-20 \mathrm{~m}$ & 330 & 5.2 & $18 \%$ & 0.016 \\
& $>20 \mathrm{~m}$ & 320 & 1.1 & $4 \%$ & 0.003 \\
\end{tabular}

${ }^{\mathrm{T}}$ Annular distance from detonation point

${ }^{2}$ Perceived density of residues on snow as determined by darkness of deposition

\section{Phase 2: Spatial distributions from detonated rounds}

The shock wave and body fragmentation from the detonations of HI-1 and HI-2 resulted in a loss of several of the sampling pans set out to collect energetic particle residues. For HI-1, the rings of pans within $3 \mathrm{~m}$ of the detonation were destroyed, and for HI-2, the pans within the first two rings were missing. There was much debris associated with the initiation system (detonation cord, blasting cap, fuze simulator) mixed in with the energetics residues, making separation difficult. However, some particles were separated and photographed. An image of high-order detonation residues particles is shown in Figure $4(\mathrm{~L})$. The particles in the image are $<<1 \mathrm{~mm}$ in their longest dimension. As distance increases from the detonation point, the number of particles decreases and the fine soot particles $(<0.25 \mathrm{~mm}$ ) dominate (Table 6). The larger particles tend to be metallic fragments or debris from the detonation with little evidence of energetics. The pattern distribution of energetics (mass) is illustrated in Figure $\mathbf{5}$ and shows a very non-uniform distribution. The presence of elevated NTO beyond $20 \mathrm{~m}$ from the detonation point indicates the presence of undetonated crystals of the compound.

For the HI-1 detonation, we swept up all the residues from $19 \mathrm{~m}$ to $25 \mathrm{~m}$ from the detonation point to determine if we could detect any energetics in the outer deposition area. Analysis of the swept deposition areas of HI-1 and HI-3 confirm that energetics deposition is quite low (Table 7). Data are compared with previous data obtained from similar command-detonation high-order tests with the same round but on snow-covered ice $(n=7)$. RDX and DNAN sample concentrations were at or just above analytical instrumentation detection limits, leading to some variability between samples. 
The percent values below the mass values for each component is the percent of that component recovered as compared to the original mass of that component in the test configuration of the munition. NTO is the only component occurring at high enough levels to possibly pick up with the pans or the outer distance sweepings $(19-25 \mathrm{~m})$.

Table 6. High-order detonation particle spatial distribution (all particles)

\begin{tabular}{|c|c|c|c|c|c|c|c|c|}
\hline Test & Distance & $\begin{array}{c}\text { Annulus } \\
\text { Area }\left(\mathrm{m}^{2}\right)\end{array}$ & $\begin{array}{c}\text { Mass }^{3} \\
(\mathrm{mg} / \%)\end{array}$ & $\begin{array}{l}>2 \mathrm{~mm} \\
(\mathrm{mg} / \#)\end{array}$ & $\begin{array}{l}1-2 \mathrm{~mm} \\
(\mathrm{mg} / \#)\end{array}$ & $\begin{array}{c}0.6-1 \mathrm{~mm} \\
(\mathrm{mg} / \#)\end{array}$ & $\begin{array}{c}0.25-0.6 \\
\mathrm{~mm}(\mathrm{mg} / \#)\end{array}$ & $\begin{array}{c}<0.25 \mathrm{~mm}^{2} \\
(\mathrm{mg} / \%)\end{array}$ \\
\hline $\mathrm{HI}-1$ & $0-4 \mathrm{~m}$ & 50 & $69 / 19$ & $0 / 0$ & $7 / 2$ & $1 / 8$ & $8 / 350 /$ & $53 / 77$ \\
\hline$(0-10 \mathrm{~m})$ & $4-5 \mathrm{~m}$ & 28 & $81 / 23$ & $0 / 0$ & $2 / 4$ & $7 / 50$ & $12 / 300^{1}$ & $60 / 74$ \\
\hline $20-\mathrm{cm}$ & $5-6 \mathrm{~m}$ & 35 & $86 / 24$ & $0 / 0$ & $12 / 3$ & $1 / 7$ & $9 / 200^{1}$ & $64 / 74$ \\
\hline \multirow[t]{6}{*}{ Pans } & $6-7 \mathrm{~m}$ & 41 & $46 / 13$ & $0 / 0$ & $<1 / 1$ & $1 / 10$ & 4/ 90 & $41 / 89$ \\
\hline & $7-8 \mathrm{~m}$ & 47 & $40 / 11$ & $0 / 0$ & $1 / 2$ & $3 / 7$ & $6 / 100^{1}$ & $30 / 75$ \\
\hline & $8-9 \mathrm{~m}$ & 53 & $22 / 6$ & $1 / 1$ & $0 / 0$ & $1 / 3$ & $1 / 110$ & $19 / 86$ \\
\hline & $9-10 \mathrm{~m}$ & 60 & $12 / 3$ & $0 / 0$ & $0 / 0$ & $1 / 3$ & $1 / 40$ & $10 / 83$ \\
\hline & Totals & 314 & $356 \mathrm{mg}$ & $1 / 1$ & $22 / 12$ & 15 & $41 / 1200$ & $280 \mathrm{mg}$ \\
\hline & Means & & $51 \mathrm{mg}$ & $-1-$ & $3 / 4 /$ & $2 / 2$ & $6 / 170$ & $40 / 80$ \\
\hline HI-1 & 19-20 m & 123 & $1300 / 42$ & $260 / 12$ & $190 / 30$ & $52 / 35$ & $120 / 300^{1}$ & $690 / 53$ \\
\hline$(>19 m)$ & $20-21 \mathrm{~m}$ & 129 & $550 / 18$ & $0 / 0$ & $190 / 36$ & $23 / 29$ & $39 / 300^{1}$ & $300 / 55$ \\
\hline \multirow[t]{7}{*}{ Swept } & $21-22 \mathrm{~m}$ & 135 & 370 / 12 & $0 / 0$ & $89 / 18$ & $17 / 13$ & $33 / 100^{1}$ & $230 / 62$ \\
\hline & $22-23 \mathrm{~m}$ & 141 & $480 / 15$ & $0 / 0$ & $69 / 12$ & $17 / 34$ & $50 / 1000^{1}$ & $340 / 71$ \\
\hline & $23-24 \mathrm{~m}$ & 148 & $220 / 7$ & $0 / 0$ & $5 / 5$ & $16 / 14$ & $14 / 200^{1}$ & 180 / 82 \\
\hline & $24-25 \mathrm{~m}$ & 154 & $140 / 5$ & $0 / 0$ & $47 / 10$ & $9 / 14$ & $10 / 200^{1}$ & $74 / 53$ \\
\hline & Totals & 830 & $3100 \mathrm{mg}$ & $260 / 12$ & $590 / 100$ & $130 / 140$ & $270 / 2100^{1}$ & $1800 \mathrm{mg}$ \\
\hline & Means & & $520 \mathrm{mg}$ & $43 / 2$ & $98 / 16$ & $22 / 23 / 4$ & $45 / 350^{1}$ & $300 / 58$ \\
\hline & & & & $\begin{array}{c}>0.6 \mathrm{~mm} \\
(\mathrm{mg} / \#)\end{array}$ & $\begin{array}{c}0.25-0.6 \\
\mathrm{~mm}(\mathrm{mg} / \#)\end{array}$ & $\begin{array}{c}0.12-0.25 \mathrm{~mm} \\
(\mathrm{mg} / \#)\end{array}$ & $\begin{array}{c}<0.12 \mathrm{~mm}^{2} \\
(\mathrm{mg} / \%)\end{array}$ & \\
\hline $\mathrm{HI}-2$ & $2-3 \mathrm{~m}$ & 16 & $1 / 2$ & $<1 / 3$ & $<1 / 20$ & $<1 / 220$ & $1 />99$ & \\
\hline$(0-10 \mathrm{~m})$ & $3-4 \mathrm{~m}$ & 22 & $2 / 3$ & $<1 / 5$ & $<1 / 100$ & $<1 / 500^{1}$ & $1 / 50$ & \\
\hline $20-\mathrm{cm}$ & $4-5 \mathrm{~m}$ & 28 & $6 / 10$ & $<1 / 1$ & $<1 / 32$ & $<1 / 120$ & $6 />99$ & \\
\hline \multirow[t]{7}{*}{ Pans } & $5-6 \mathrm{~m}$ & 35 & $10 / 17$ & $<1 / 4$ & $<1 / 42$ & $<1 / 450^{1}$ & $9 / 90$ & \\
\hline & $6-7 \mathrm{~m}$ & 41 & $10 / 17$ & $<1 / 1$ & $<1 / 2$ & $<1 / 60$ & $9 / 90$ & \\
\hline & $7-8 \mathrm{~m}$ & 47 & $9 / 16$ & $<1 / 1$ & $<1 / 60$ & $0 / 0$ & $8 / 89$ & \\
\hline & $8-9 \mathrm{~m}$ & 53 & $10 / 17$ & $<1 / 4$ & $<1 / 24$ & $<1 / 15$ & $10 />99$ & \\
\hline & $9-10 \mathrm{~m}$ & 60 & $10 / 17$ & $3 / 3$ & $<1 / 4$ & $<1 / 20$ & $8 / 80$ & \\
\hline & Totals & 302 & $58 \mathrm{mg}$ & $\approx 5 / 19$ & $\approx 4 / 36$ & $\approx 4 / 170$ & $52 \mathrm{mg}$ & \\
\hline & Means & & $7.3 \mathrm{mg}$ & $\approx 0.6 / 2$ & $\approx 0.5 / 5$ & $\approx 0.5 / 21$ & $6.5 / 89$ & \\
\hline
\end{tabular}

${ }^{\mathrm{I}}$ Estimate based on partial count of particles

${ }^{2}$ Rough order of magnitude estimate is in the thousands of particles (Particles were clumped together)

${ }^{3}$ Total mass of particles following measurement

Table 7. Estimated total detonation residues

\begin{tabular}{lccc}
\hline Test & $\begin{array}{l}\text { RDX } \\
(\mathrm{mg})\end{array}$ & $\begin{array}{l}\text { DNAN } \\
(\mathrm{mg})\end{array}$ & $\begin{array}{l}\text { NTO } \\
(\mathrm{mg})\end{array}$ \\
\hline HI-1 & 7.8 & 32 & 720 \\
$(\%$ Original mass $)$ & $(0.006 \%)$ & $(0.013 \%)$ & $(0.17 \%)$ \\
HI-3 & 0.4 & 1.2 & 730 \\
$(\%$ Original mass) & $(<0.001 \%)$ & $(<0.001 \%)$ & $(0.17 \%)$ \\
Prior Tests & 7.7 & 7.9 & 540 \\
$(\%$ Original mass $)$ & $(0.006 \%)$ & $(0.003 \%)$ & $(0.13 \%)$ \\
\hline
\end{tabular}




\section{Phase 3: Unconfined charge dispersion}

The distribution of energetics from the unconfined charge dispersion tests was not symmetrical. Figure 6 depicts the mass distribution based on captured residues in pans located in the various sectors of the witness plate below the detonation point. The deposition pattern is not uniform and the highest mass is not below the detonation point. These characteristics run counter to the model prediction. Also, the mass collected further from the detonation point indicates a more extensive distribution that the model predicted. The plot is a mean of three tests, and tests at $2.5 \mathrm{~g}$ and $5 \mathrm{~g}$ both exhibit similar distribution patterns.

\section{Discussion}

Field research on high-order detonation residues dispersal indicates that uniform radial distribution of particles rarely occurs. The very small size of the particles, both energetic and metallic, makes them very susceptible to directional dispersal effects of atmospheric conditions, especially wind. The dispersal patterns for the high-order detonations shown in Figure 1 are near ideal. More typical are the deposition areas depicted in Figure 7, with the detonation craters (small circular areas) offset from the center of the plumes.

Post-detonation residues within a deposition area also do not occur as a uniform gradient from the detonation point. Wind, thermodynamic effects of the detonation fireball, and detonation kinetics all affect the dispersal of residues, resulting in non-uniform distribution of the particles (Figure 8). Crater (detonation point) residues also tend to be low for live-fired rounds, resulting in areas of up to $10 \mathrm{~m}^{2}$ at the detonation point without any detectable energetics [5][42]. Sampling of residues within concentric areas centered on detonation points does show a consistently decreasing deposition amount as the distance increases, but there will be great variability within each concentric area in the mass density of residues.

The particle dispersion data from the command-detonated mortar rounds further substantiates the nonhomogeneous nature of resides deposition from high-order detonations. For our tests, the mass deposition peaks around 5-6 $\mathrm{m}$ from the detonation point, demonstrating that proximity to the crater does not necessarily correlate with maximum energetics residues deposition. The residues mass feathers out as distance increased beyond $6 \mathrm{~m}$, as most models would predict. However, the mass of energetics did not peak until more than $20 \mathrm{~m}$ from the detonation point, where the mass of NTO residues rapidly rose and then fell. It would be interesting to repeat this test with different size rounds and with swept annuli rather than small pans to get a better indication of particle distribution.

The series of tests conducted at Cranfield University with unconfined charges using residue capture plates were designed based on a computational blast modeling software tool called ProSAir [33]. The particle distribution pattern did not match the predicted pattern, more resembling the results found during the Phase 2 testing described above. Although the model gave a useful rough estimate of the mass distribution, the Cranfield research demonstrates that further fieldwork is required to generate the empirical data needed to fine tune currently used deposition models.

Most rounds fired into impact ranges function properly, detonating high order. Past research indicates that high-order detonations of conventional munitions contribute only a small amount of energetics contamination on ranges [23]. A single low-order detonation will result in four to five orders of magnitude more energetic residues that a high-order detonation, thus dominating energetics sources on military training ranges [1][3][23]. The very fine residues from high-order detonations are subject to quick dissolution because of a high surface area to mass ratio [43]. However, the very small amount of energetic material contained in the 
residues is more easily attenuated by natural processes. To better characterize and model energetics deposition on training ranges, low-order detonations will need to be addressed, especially for the emerging insensitive munitions with their higher energetics deposition and highly soluble energetic compounds [13-17].

Data from only a few high-order detonation tests are obviously not sufficient to optimize current models, and there is a need to incorporate low-order and partial detonation data. More field-testing of munitions needs to be conducted to generate a meaningful empirical database. These data can then be used to modify current models [19]. Finally, tests in Phase 2 and Phase 3 were conducted on smooth surfaces. The very fine residues from the high-order detonations may be skewed away from the detonation points as a result of lateral transport caused by the shock wave and the expanding gases from the detonation. A testing protocol needs to be developed to determine if kinetic transport is an unwanted factor in the determination of residues distribution.

\section{Summary}

Energetic particle dispersion from high-order detonations is a complex process that does not lend itself to simple modeling. Many factors affecting particle dispersion are not included in current models. These models have been modified based on available particle dispersion data, but the data are limited and need to be supplemented with additional empirical data. Data presented in this paper on particle dispersion areas, distance-related mass deposition data, and mass deposition based on perceived density of residues deposition can all be used to further refine modeling of high-order detonation deposition of energetics. Particle counts and mass of energetics based on radial distances from detonation are presented that will also assist in refining dispersion models. Previous research indicates that low-order detonations contribute most of the energetics readily available on ranges, thus residues data from these detonations must be incorporated in models to make them relevant for predicting environmental impacts on training ranges from live-fire munitions. 


\section{References}

[1] Jenkins, TF, AD Hewitt, CL Grant, S Thiboutot, G Ampleman, ME Walsh, TA Ranney, CA Ramsey, AJ Palazzo and JC Pennington (2006). Identity and distribution of residues of energetic compounds at army live-fire training ranges. Chemosphere, 63: 1280-1290.

[2] Kelleher, JD (2002). Explosive Residue: Origin and Distribution. Forensic Science Communications, Vol. 4, No. 2, April 2002. US Federal Bureau of Investigation, Washington, DC, USA. Available from: http://www.fbi.gov/about-us/lab/forensic-sciencecommunications/fsc/april2002/kelleher.htm. [Accessed July 2016]

[3] Pichtel, J (2012) Distribution and fate of military explosives and propellants in soil: A review. Applied and Environmental Soil Science, vol. 2012, Article ID 617236, 33 pages, 2012. doi:10.1155/2012/617236.

[4] Thiboutot, S, G Ampleman, S Brochu, E Diaz, R Martel, J Hawari, G Sunahara, MR Walsh, and ME Walsh (2013) Canadian programme on the environmental impacts of munitions. 1st European Conference on Defence and the Environment, Helsinki, Finland.

[5] Hewitt, AD, TF Jenkins, ME Walsh, MR Walsh, and S Taylor (2005). RDX and TNT residues from live-fire and blow-in-place detonations. Chemosphere 61: 888-894.

[6] Walsh, MR, ME Walsh, and AD Hewitt (2010) Energetic residues from field disposal of gun propellants. J Hazard Mater, 173: 115-122.

[7] Walsh, MR, ME Walsh, and ØA Voie (2014) Presence and persistence of white phosphorus on military training ranges. Propell, Explos, Pyrot. 39(6): 922-931.

[8] Walsh, ME, MR Walsh, CM Collins, CH Racine (On-line May 2014) White phosphorus contamination of an active army training range. Water Air Soil Pollut. (2014) 225:2001.

[9] Lever, JH, S Taylor, L Perovich, K Bjella, and B Packer (1995) Dissolution of Composition B detonation residuals. Environ. Sci. Technol. 2005(39): 8803-8811.

[10] Walsh, ME, S Taylor, AD Hewitt, MR Walsh, CA Ramsey, and CM Collins (2010) Field observations of the persistence of Comp B explosives residues in a salt marsh impact area. Chemosphere 78: 467-473.

[11] Racine, C.H., M.E. Walsh, B.D. Roebuck, C.M. Collins, D.J. Calkins, L.R. Reitsma, P.J. Buchli, and G. Goldfarb (1992) White phosphorus poisoning of waterfowl in an Alaskan salt marsh. Journal of Wildlife Diseases, 28(4): 669-673.

[12] Clausen, J. Robb, D. Curry, and N. Korte (2004) A case study of contaminants on military ranges: Camp Edwards, Massachusetts, USA. Environmental Pollution, 129(2004): 13 - 21.

[13] Walsh, MR, ME Walsh, S Taylor, CA Ramsey, and DB Ringelberg (2013) Characterization of PAX-21 insensitive munitions detonation residues. Propell, Explos, Pyrot., 38: 399-409.

[14] Walsh, ME, MR Walsh, S Taylor, and CA Ramsey (2014) Deposition of DNAN and RDX from PAX-21 and IMX-104 Detonations. Proceedings of the JANNAF Workshop on Insensitive Munitions 2014: 23-31.

[15] Walsh, MR, ME Walsh, CA Ramsey, S Thiboutot, G Ampleman, E Diaz, JE Zufelt (2014) Energetic residues from the detonation of IMX-104 insensitive munitions, Propell, Explos, Pyrot., 38(2): $243-250$.

[16] Taylor S, DB Ringelberg, K Dontsova, C Daghlian, ME Walsh and MR Walsh (2013) Insights into the dissolution and the three-dimensional structure of Insensitive Munitions Formulations, Chemosphere, 93: $1782-1788$. 
[17] Walsh, MR, ME Walsh, CA Ramsey, S Brochu, S Thiboutot, and G Ampleman (2013) Perchlorate contamination from the detonation of insensitive high-explosive rounds, J Hazard Mater. 262(2013): 228-233.

[18] SERDP/ESTCP (2016) Environmental Restoration Program : Range contamination. Found at : https://www.serdp-estcp.org/Program-Areas/Environmental-Restoration/Contaminants-onRanges (Accessed 12 JUL 2016).

[19] Hathaway, JE, JP Rishel, ME Walsh, MR Walsh, S Taylor (2015) Explosive particle soil surface dispersion model for detonated military munitions. Environ Monit Assess 187(7): 1-15.

[20] Montanaro, PE (1990) TRAJ-A two-dimensional trajectory program for personal computers. Washington: Naval Surface Warfare Center.

[21] Crull, MM (1998) Prediction of primary fragmentation characteristics of cased munitions. USAESC Report No. 500203. U.S. Army Engineering \& Support Center, Huntsville, AL USA.

[22] Interstate Technology and Regulatory Council (ITRC) (2011). Incremental sampling methodology: Representative sampling, confident decisions. Found at: www.itrcweb.org/ism-1. (Accessed 12 JUL 2016).

[23] Walsh, MR, ME Walsh, I Poulin, S Taylor, and TA Douglas (2011) Energetic residues from the detonation of common US ordnance, Int. J. Energ. Mater. Chem. Propul. 10(2): 169-186.

[24] Walsh, MR, ME Walsh, G Ampleman, S Thiboutot, S Brochu, and TF Jenkins (2012). Munitions propellants residue deposition rates on military training ranges, Propell, Explos, Pyrot. 37(4): 393-406.

[25] Taylor, S, AD Hewitt, JH Lever, C Hayes, L Perovich, P Thorn, and C Daghlian (2004). TNT particle size distributions from detonated 155-mm howitzer rounds. Chemosphere, 55, 357-367.

[26] Yallop, HJ (1980). Explosion Investigation Forensic Science Society, Harrogate, North Yorkshire, UK.

[27] Walsh, MR, ME Walsh, CA Ramsey, RJ Rachow, JE Zufelt, CM Collins, AB Gelvin, NM Perron, and SP Sarri (2006) Energetic residues deposition from 60-mm and 81-mm mortars. ERDC/CRREL Technical Report TR-06-10. US Army Cold Regions Research and Engineering Laboratory (USA CRREL), Hanover, NH USA.

[28] Dauphine, L, and C Doyle (2000) USACE Report of findings for: Study of ammunition dud and low-order detonation rates. Report SFIM-AEC-ET-CR-200049. US Army Environmental Center (USAEC), Aberdeen Proving Ground, MD.

[29] Dauphine, L, C Doyle (2001) USACE Report of findings for: Phase II study of ammunition dud and low-order detonation rates. Report SFIM-AEC-PC-CR-200139. USAEC, Aberdeen Proving Ground, MD.

[30] Bishop, RH (1958) Maximum Missile Ranges from Cased Explosive Charges. Report No. SC4205 (TR). Sandia National Laboratories (SNL), Albuquerque, New Mexico, USA.

[31] Kennedy, JE (1970) Gurney Energy of Explosives: Estimation of the Velocity and Impulse Imparted to Driven Metal. Report No. SC-RR-70-90. SNL, Albuquerque, NM, 1970.

[32] Abdul-Karim, N, R Morgan, R Binions, T Temple, and K Harrison, (2013) The Spatial Distribution of Post-blast RDX Residue: Forensic Implications. J Forensic Sci 58(2)2 365-371. DOI: 10.1111/1556-4029.12045. 
[33] Lindkvist, G, and SA Forth (2016) ProSAir Computational Blast Loading Tool. Cranfield University, Shrivenham, UK. Available from: http://www.cranfield.ac.uk/facilities/cds-prosaircomputational-blast-loading-tool (Accessed 12 JUL 2016).

[34] Jenkins, TF, ME Walsh, PH Miyares, AD Hewitt, NH Collins, and TA Ranney (2002) Evaluation of the use of snow-covered ranges to estimate the explosives residues that result from high order detonations of army munitions. Thermochemica Acta, 384: 173-185.

[35] Walsh, MR, ME Walsh, and CA Ramsey (2012) Measuring energetic contaminant deposition rates on snow. Water Air Soil Pollut (2012) 223:3689-3699.

[36] Walsh, MR, ME Walsh, CA Ramsey, and TF Jenkins (2005) An examination of protocols for the collection of munitions-derived explosives residue on snow-covered ice. ERDC/CRREL Technical Report TR-05-8. USA CRREL, Hanover, NH USA.

[37 North Atlantic Treaty Organization (2010) Guidance on the assessment and development of insensitive munitions. NATO Standardization Agency, Defence Investment Division, Allied Ordnance Publication AOP-39, pp. I-1 to I-4. NATO Standardization Organization, Brussels, BEL.

[38] US Department of Defense (1994) Hazard assessment tests for non-nuclear munitions (14 JUL 2003 update). US DoD Test Method Standard MIL-STD-2105C, pp 7-8. US Department of Defense, Washington, DC.

[39] Walsh, ME (2016) Analytical methods for insensitive high explosives. J Energ. Mater. 34: 76 -91 .

[41] USEPA, Nitroaromatics and Nitramines by High-Pressure Liquid Chromatography, EPA SW846 Method 8330B, 2006, US Department of Environmental Protection, Washington, DC (Accessed May 2013): (http://www.epa.gov/osw/hazard/testmethods/pdfs/8330b.pdf).

[42] Walsh, MR (2016) Energetics residues from the detonations of IMX-101 and IMX-104 munitions. ERDC/CRREL Test Report (Distribution limited). USA CRREL, Hanover, NH USA.

[43] Hewitt, AD, TF Jenkins, TA Ranney, JA Stark, ME Walsh, S Taylor, MR Walsh, DJ Lambert, NM Perron, NH Collins, and R Karn (2003) Estimates for exploisves residue from the detonation of army munitions. ERDC/CRREL Technical Report TR-03-16. USA CRREL, Hanover, NH USA.

[44] Taylor, S, JH Lever, J Fadden, N Perron, and B Packer (2009) Simulated rainfall-driven dissolution of TNT, Tritonal, Comp B, and Octol particles. Chemosphere 75(2009): 1074-1081. 


\section{Figures}

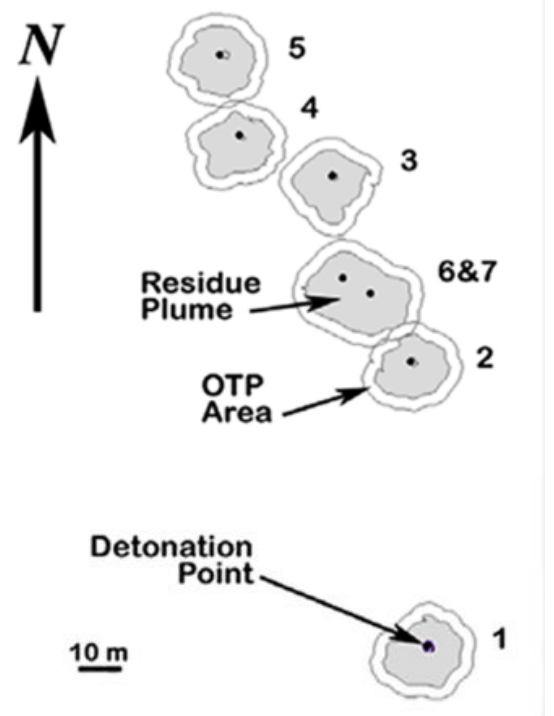

Figure 1. Residues deposition area outlines for 60-mm mortar round detonations [26]

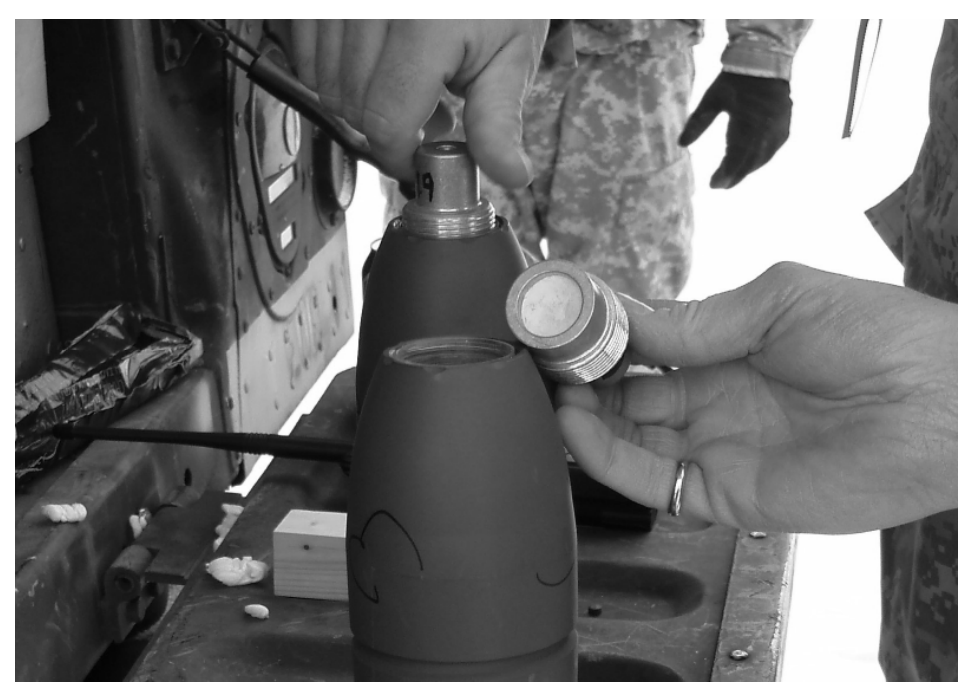

Figure 2. Installing fuze simulators in 81-mm mortar rounds. Note C4 explosive in base of simulator and hole for blasting cap on top of the simulator. 


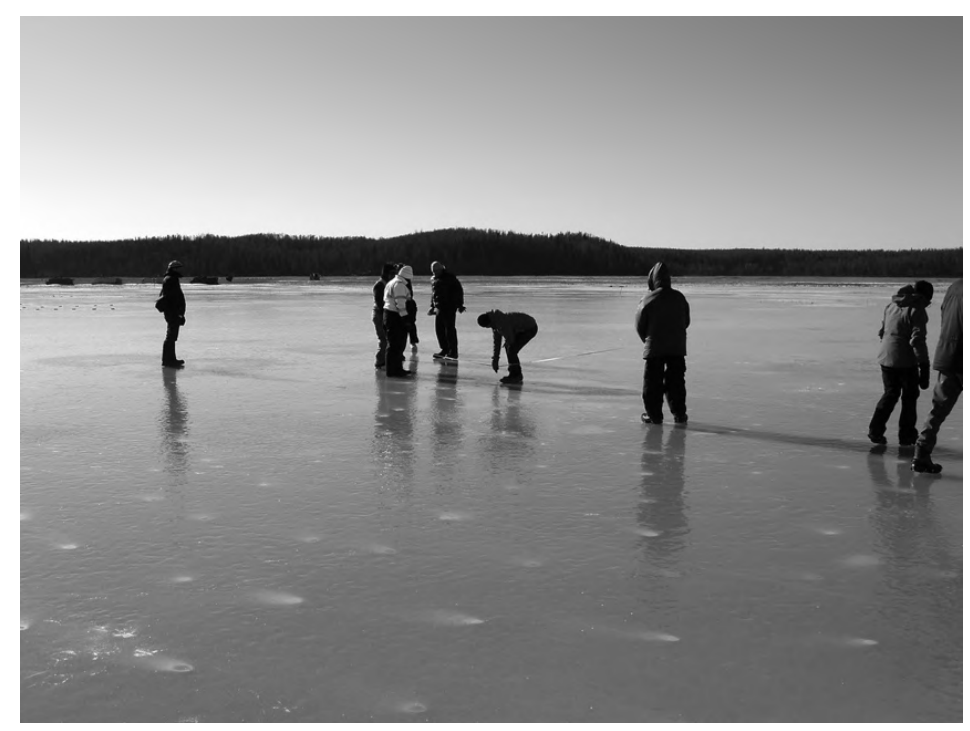

Figure 3. Painting concentric circle marks on ice surface for detonation tests.
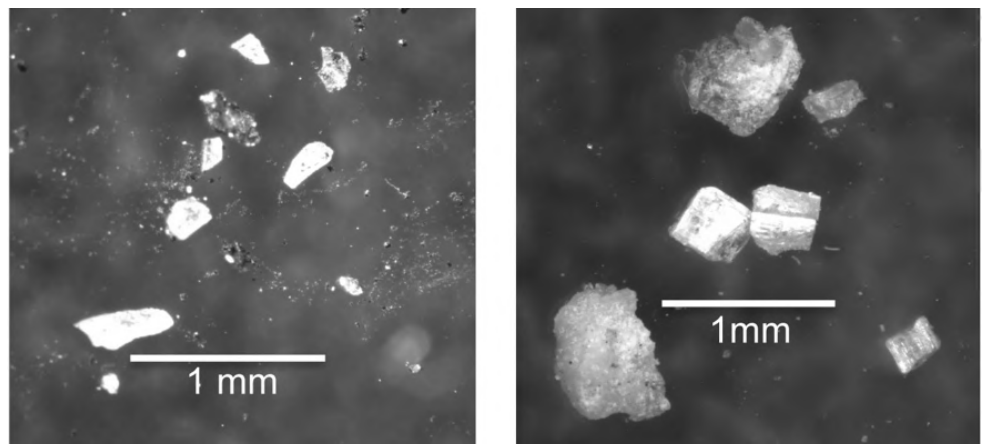

Figure 4. Photomicroscopic images of particles recovered after a high-order (L) and a loworder (R) detonation (Courtesy S. Taylor, CRREL).

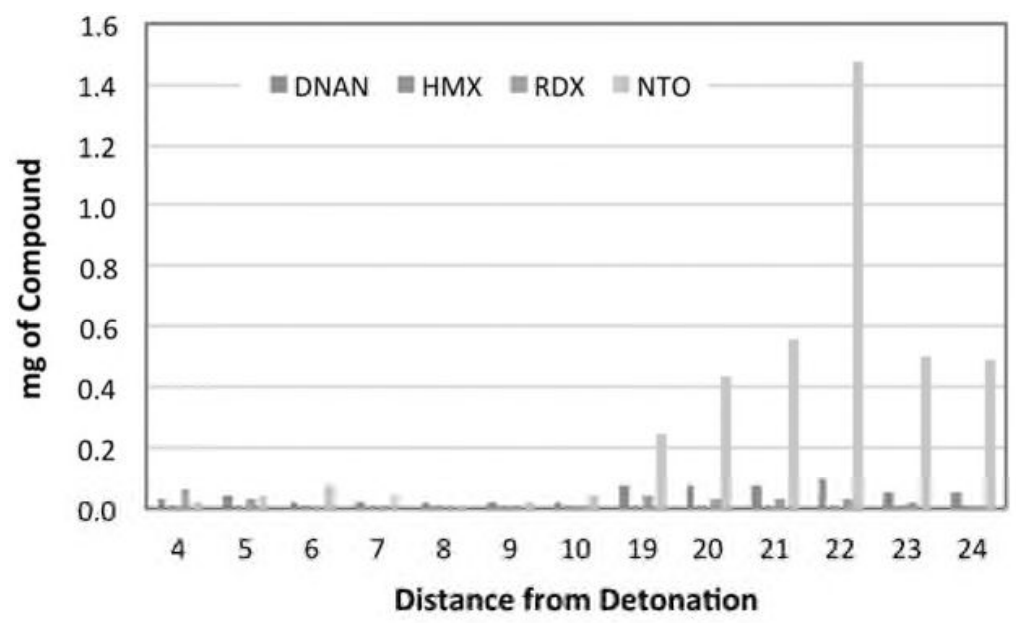

Figure 5. Mass distribution of energetics in residues particles collected from pans following a high-order detonation. 

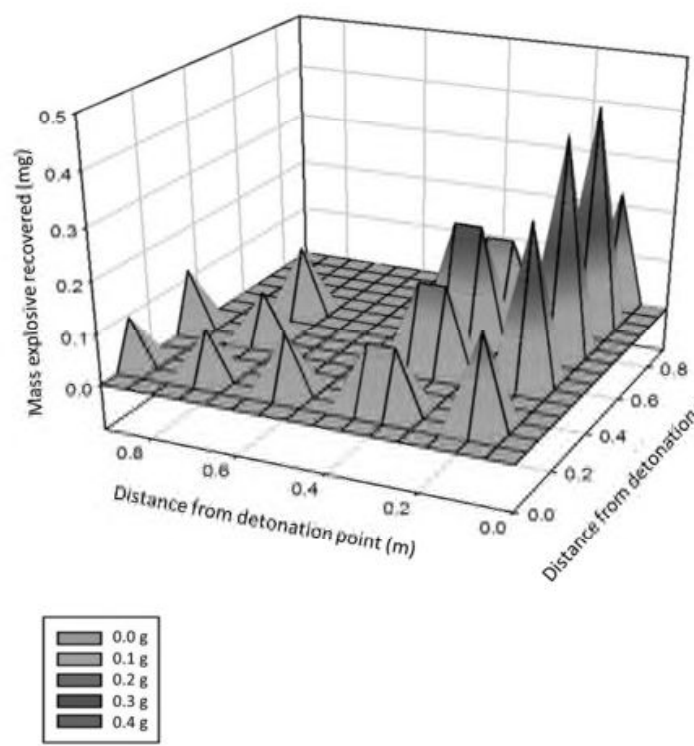

Figure 6. Mean particle distribution for unconfined $2.5 \mathrm{~g}$ detonation (3 tests). Distances are in meters.

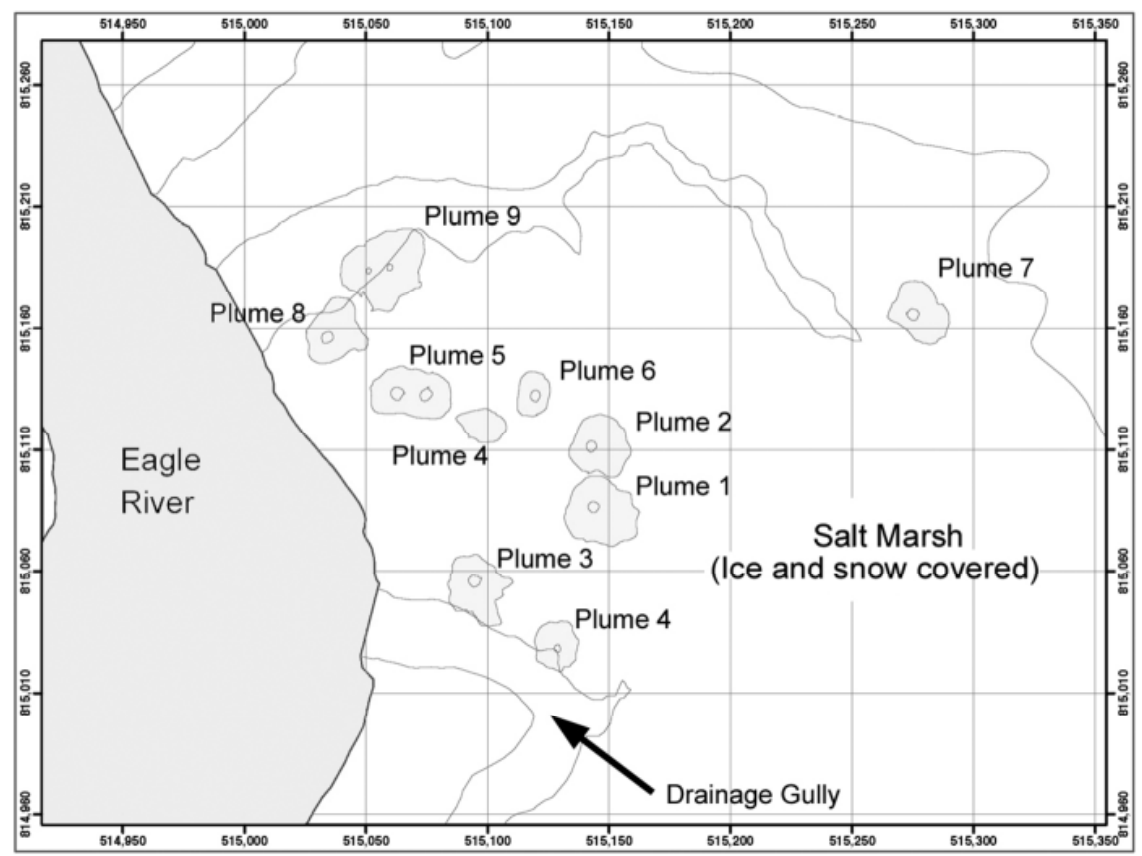

Figure 7. Wind-influenced high-order detonation plumes. 


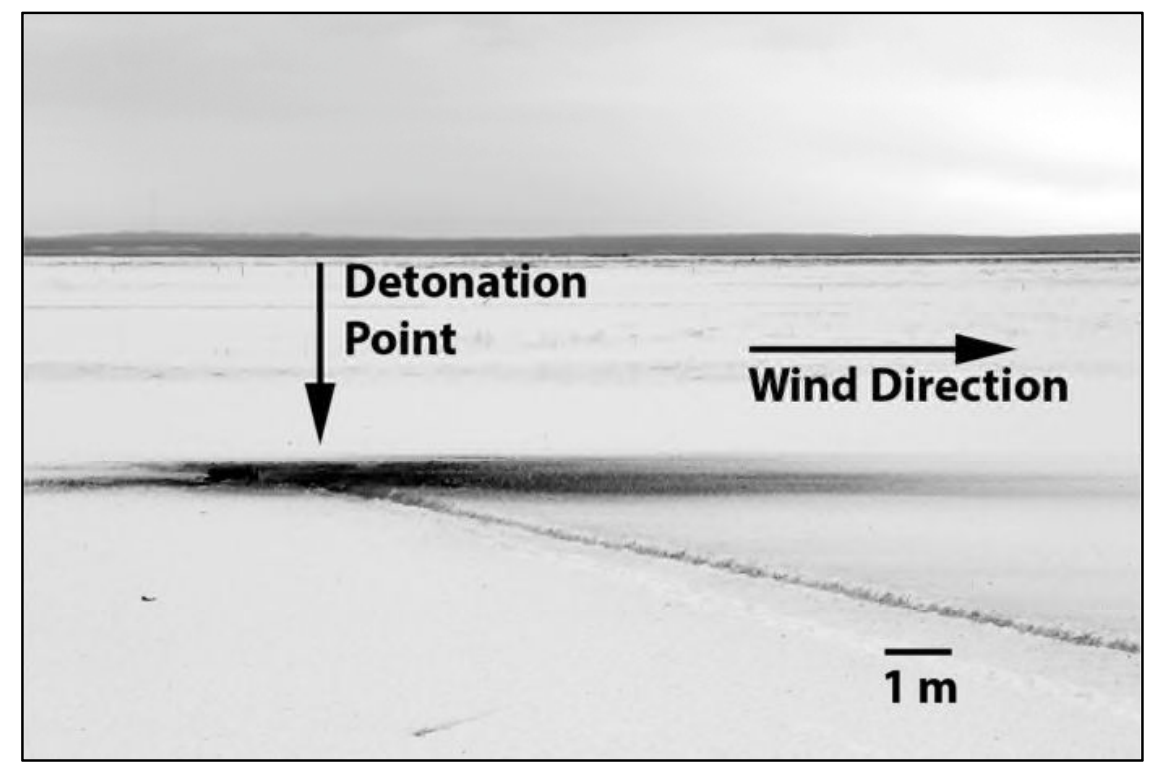

Figure 8. Residues distribution from a high-order detonation. 